\title{
Is it possible to assess the best mitral valve repair in the individual patient? Preliminary results of a finite element study from magnetic resonance imaging data
}

\author{
Francesco Sturla, MSc, ${ }^{\mathrm{a}, \mathrm{b}}$ Francesco Onorati, MD, PhD, ${ }^{\mathrm{a}}$ Emiliano Votta, $\mathrm{PhD},{ }^{\mathrm{b}}$ \\ Konstantinos Pechlivanidis, MD, ${ }^{\mathrm{a}}$ Marco Stevanella, PhD, ${ }^{\mathrm{b}}$ Aldo D. Milano, MD, ${ }^{\mathrm{a}}$ \\ Giovanni Puppini, MD, ${ }^{\mathrm{c}}$ Alessandro Mazzucco, $\mathrm{MD},{ }^{\mathrm{a}}$ Alberto Redaelli, $\mathrm{PhD},{ }^{\mathrm{b}}$ and Giuseppe Faggian, $\mathrm{MD}^{\mathrm{a}}$
}

\begin{abstract}
Objectives: Finite element modeling was adopted to quantitatively compare, for the first time and on a patientspecific basis, the biomechanical effects of a broad spectrum of different neochordal implantation techniques for the repair of isolated posterior mitral leaflet prolapse.
\end{abstract}

\begin{abstract}
Methods: Cardiac magnetic resonance images were acquired from 4 patients undergoing surgery. A patientspecific 3-dimensional model of the mitral apparatus and the motion of the annulus and papillary muscles were reconstructed. The location and extent of the prolapsing region were confirmed by intraoperative findings, and the mechanical properties of the mitral leaflets, chordae tendineae and expanded polytetrafluoroethylene neochordae were included. Mitral systolic biomechanics was simulated under preoperative conditions and after 5 different neochordal procedures: single neochorda, double neochorda, standard neochordal loop with 3 neochordae of the same length and 2 premeasured loops with 1 common neochordal loop and 3 different branched neochordae arising from it, alternatively one third and two thirds of the entire length.
\end{abstract}

Results: The best repair in terms of biomechanics was achieved with a specific neochordal technique in the single patient, according to the location of the prolapsing region. However, all techniques achieved a slight reduction in papillary muscle forces and tension relief in intact native chordae proximal to the prolapsing region. Multiple neochordae implantation improved the repositioning of the prolapsing region below the annular plane and better redistributed mechanical stresses on the leaflet.

Conclusions: Although applied on a small cohort of patients, systematic biomechanical differences were noticed between neochordal techniques, potentially affecting their short- to long-term clinical outcomes. This study opens the way to patient-specific optimization of neochordal techniques. (J Thorac Cardiovasc Surg 2014;148:1025-34)

Degenerative mitral valve (MV) prolapse is the most common mitral disease in western countries. ${ }^{1}$ Posterior leaflet prolapse is the most common pathologic feature of a degenerative MV. Several conservative surgical techniques have become popular, the first of which dates back to $1983 .^{2}$ However, recent studies have demonstrated comparable clinical outcomes, together with potentially superior results in terms of physiology, with techniques that respect rather than resect the diseased portion of the MV. ${ }^{3}$ Most of these techniques rely on the use of neochordal implantation

\footnotetext{
From the Division of Cardiovascular Surgery, ${ }^{\mathrm{a}}$ Università degli Studi di Verona, Verona; Department of Electronics, Informatics and Bioengineering, ${ }^{\mathrm{b}}$ Politecnico di Milano, Milan; Department of Radiology, ${ }^{\mathrm{c}}$ Università degli Studi di Verona, Verona, Italy.

Disclosures: Authors have nothing to disclose with regard to commercial support. Read at the 94th Annual Meeting of The American Association for Thoracic Surgery, Toronto, Ontario, Canada, April 26-30, 2014.

Received for publication April 9, 2014; revisions received May 21, 2014; accepted for publication May 27, 2014; available ahead of print July 19, 2014.

Address for reprints: Francesco Sturla, MSc, PhD Program in Cardiovascular Sciences, University of Verona Medical School, Department of Electronics, Informatics and Bioengineering, Politecnico di Milano, Via Golgi 39, 20133 Milano, Italy (E-mail: francesco.sturla@univr.it or francesco.sturla@mail.polimi.it). $0022-5223 / \$ 36.00$

Copyright (c) 2014 by The American Association for Thoracic Surgery http://dx.doi.org/10.1016/j.jtcvs.2014.05.071
}

(NCI); its principal drawback is related to the precise assessment of neochordal length during surgical intervention. ${ }^{4,5}$ For that reason, several techniques have been used to correctly measure neochordal length, fundamentally based on anatomical in vivo measurement in the beating heart using transesophageal echocardiography ${ }^{6}$ or functional in vivo measurement in the standstill heart with intermittent saline injection. ${ }^{7}$ Furthermore, single ${ }^{8}$ and multiple neochordal stitching have been reported. ${ }^{9}$ These techniques have been proved effective in the relief of MV prolapse and associated with excellent mid- to long-term outcomes. ${ }^{10}$

Although in the last few decades finite element (FE) modeling has been increasingly adopted to study the mitral valve and quantify its biomechanics, under both physiologic and pathologic conditions, ${ }^{11}$ few literature studies have addressed the impact of NCI on MV biomechanics using the FE technique. ${ }^{12-14}$ A pioneer study was performed by Kunzelman and colleagues ${ }^{13}$ on a paradigmatic MV model derived from fresh porcine hearts. A more recent study ${ }^{14}$ overcame the shortcomings of previous paradigmatic FE models via a computational protocol able to virtually simulate the effects of increasing the number of artificial sutures, although based on a single MV geometry. 


$\begin{array}{ll}\text { Abbreviations and Acronyms } \\ \text { cMRI } & =\text { cardiac magnetic resonance imaging } \\ \mathrm{CoA} & =\text { coaptation area } \\ \mathrm{CoL} & =\text { coaptation length } \\ \mathrm{DN} & =\text { double neochordal implantation } \\ \mathrm{ePTFE} & =\text { expanded polytetrafluoroethylene } \\ \mathrm{F}_{\mathrm{ePTFE}} & =\text { artificial suture tension } \\ \mathrm{F}_{\mathrm{nc}} & =\text { native chordal tension } \\ \mathrm{F}_{\mathrm{PM}} & =\text { papillary muscles forces } \\ \mathrm{FE} & =\text { finite element } \\ \mathrm{FED} & =\text { fibroelastic deficiency } \\ \mathrm{IPP} & =\text { isolated posterior leaflet prolapse } \\ \mathrm{MV} & =\text { mitral valve } \\ \mathrm{LN} & =\text { nonstandard premeasured neochordal } \\ & \text { implantation with common loop of } \\ \mathrm{LNH} & \text { one third of the entire length } \\ & \text { imonstandard premeasured neochordal } \\ & \text { two thirds of the entire length } \\ \mathrm{NCI} & =\text { neochordal implantation } \\ \mathrm{PM} & =\text { papillary muscle } \\ \text { Pre-model } & =\text { preoperative model } \\ \mathrm{Phys}-\mathrm{model} & =\text { physiologic model } \\ \mathrm{S}_{\mathrm{I}} & =\text { maximum principal stress } \\ \mathrm{S}_{\mathrm{I}}{ }^{\mathrm{MAX}} & =\text { peak value of maximum principal } \\ \mathrm{SL} & \text { stresses along the leaflet free margin } \\ \mathrm{SN} & =\text { standard loop implantation } \\ & =\text { single neochordal implantation } \\ & \end{array}$

However, no study has ever investigated the biomechanics underlying the above-mentioned spectrum of different surgical NCI techniques and, in particular, using a patient-specific multidisciplinary approach combining bioengineering, radiological, and surgical methods. Therefore, it was the aim of this study to investigate degenerative MVs with isolated $\mathrm{P} 2$-scallop prolapse using a computational evaluation protocol based on the FE method and combining patient-specific MV modeling from cardiac magnetic resonance imaging (cMRI) and intraoperative surgical findings to assess the biomechanical effects of different clinical scenarios of P2 prolapse, as well as of different surgical techniques for NCI.

\section{MATERIALS AND METHODS}

The outline of the developed framework is reported qualitatively in Figure 1. The analysis process involved different tasks, as detailed in the following sections.

\section{cMRI Acquisition}

Four patients scheduled for surgical repair of isolated posterior leaflet prolapse (IPP) caused by fibroelastic deficiency (FED) were enrolled in the study (Table 1) at a single university hospital. As per protocol, all patients were in stable sinus rhythm preoperatively. These patients were chosen from 20 contemporary cases of MV P2 prolapse analyzed by cMRI because of the different mechanisms underlying a common functional isolated $\mathrm{P} 2$ prolapse. In detail, patient 1 had rupture of a single primary chorda arising from the posteromedial papillary muscle (PM) and anchoring on the midportion of $\mathrm{P} 2$; patient 2 had a triple primary chordal rupture, also arising from the posteromedial $\mathrm{PM}$ and anchoring on mid-P2; patient 3 had a single primary chordal rupture arising from the posteromedial PM and anchoring at the cleft area of P2 next to P3 scallop; patient 4 had a single primary chordal rupture arising from the anterolateral PM and anchoring on mid-P2.

At each preoperative acquisition, cine cMRI images were acquired on 18 cut planes evenly rotated around the axis passing through the annular center and aligned with the left ventricle long axis (Figure 1, 1). Thirty cardiac frames were acquired on each plane, with different temporal resolution according to the R-R interval of each patient; cMRI images were acquired using a 3.0-T TX Achieva system (Philips Medical System, Irvine, Calif) with a pixel spacing of $1.25 \mathrm{~mm}$ and a slice thickness of $8 \mathrm{~mm}$.

\section{Three-Dimensional cMRI-Derived MV Model}

The cMRI quantification of the MV apparatus was accomplished using a standardized published technique. ${ }^{15}$ Briefly, segmentation of the set of images was realized using dedicated software developed in MATLAB (The MathWorks Inc, Natick, Mass). The position of reference points for relevant MV substructures (ie, mitral annulus, leaflet free margin, and PMs) was selected manually within the set of images. The coordinates of the points identified were then automatically transformed in the threedimensional (3D) space using the information stored in the appropriate DICOM fields in order to reproduce a complete and patient-specific 3D geometric model of the MV apparatus. Moreover, segmentation of the set of cine cMRI images allowed the motion of both the mitral annulus and $\mathrm{PMs}$ to be tracked throughout the R-R interval. Relevant parameters were then computed from the 3D model obtained in order to assess MV geometry at the midsystolic frame (Table 1).

The initial stress-free MV geometry was reconstructed with reference to end diastole (ie, the last frame preceding closure of the leaflets) and following the approach proposed by Stevanella and colleagues ${ }^{15}$ : a complete 3D model of the mitral apparatus was reconstructed at the selected frame, including the extent of each MV leaflet and the chordal apparatus, defined in accordance with ex vivo findings, ${ }^{16-18}$ previous work by the group, ${ }^{11,15}$ and in particular the appearance of the heart during surgery. Intraoperative measurements were carried out during surgery in order to assess the length of individual posterior and anterior scallops and the height of the anterior and posterior commissures. Moreover, the exact location and extent of the prolapsing region were defined and further details on the IPP lesion were added: (1) the number and type (first, second, third order) of the chordae involved; (2) individual rupture or elongation; (3) PM origin of ruptured/elongated chordae; (4) P2-scallop insertion of ruptured/elongated chordae.

\section{Simulation Setup}

The simulation setup was performed as already detailed in previous works. ${ }^{15}$ MV 3D numerical models were completed including the mathematical description of the complex mechanical properties of MV leaflets, ${ }^{19}$ native chordae tendineae, ${ }^{20}$ and expanded polytetrafluoroethylene (ePTFE) neochordae. ${ }^{21,22}$ All simulations were carried out using the commercial solver ABAQUS Explicit 6.10 (SIMULIA; Dassault Systèmes, Providence, RI). MV closure was simulated from end diastole to peak systole, defined as the midsystolic frame within the R-R interval.

\section{Suture Length and NCI}

For each cMRI-derived model, the systolic MV biomechanics was first simulated, reproducing the preoperative scenario of MV lesions and dysfunctions (Pre-model). From the Pre-model, a physiologic MV model (Phys-model) was derived, which was characterized by complete and intact 
1) cMRI acquisition

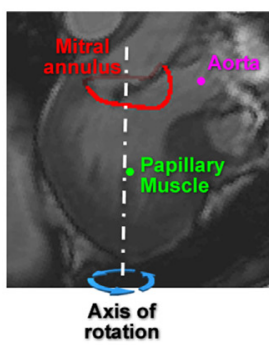

2) cMRI-derived MV Pre-model

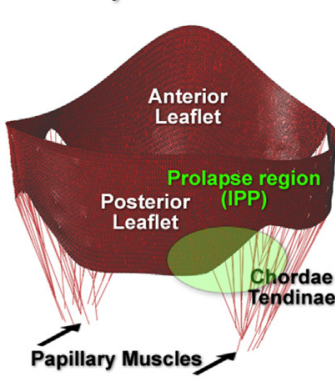

\section{3) MV Phys-model}
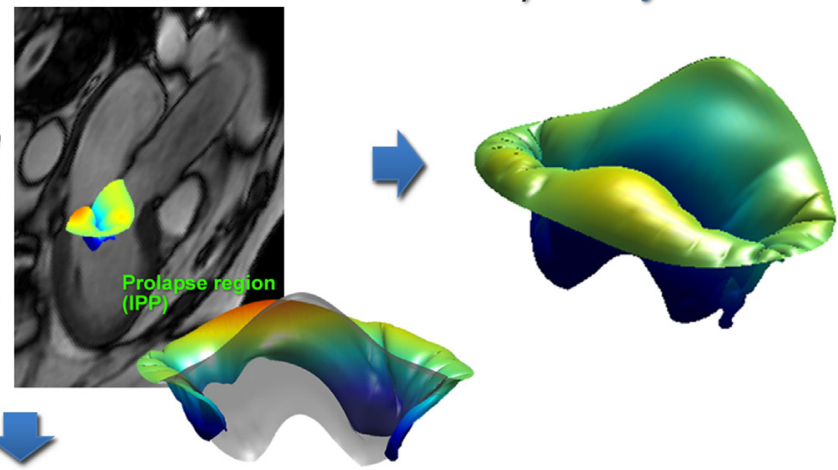

\section{.}

4) Simulations of different Neochordal Implantations (NCIs)

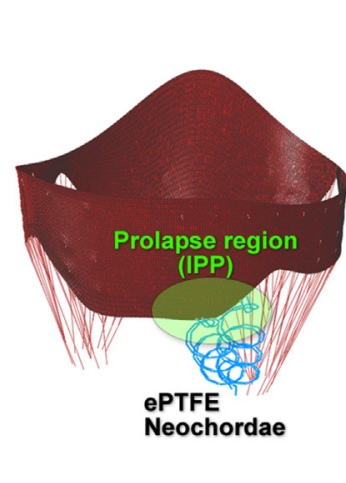

a) $S N$

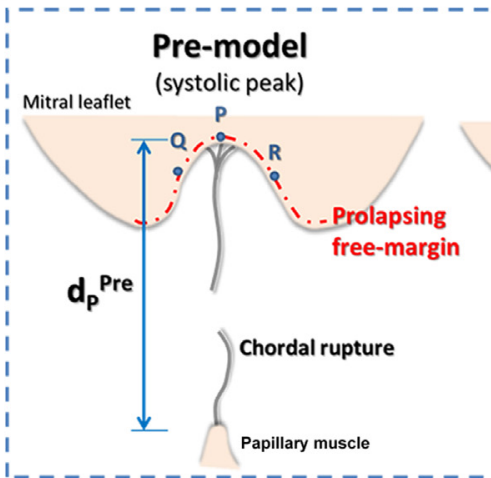

b) DN

c) SL

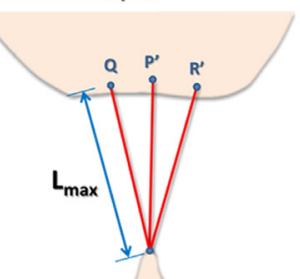

\begin{abstract}
Phys-model
(systolic peak)
\end{abstract}

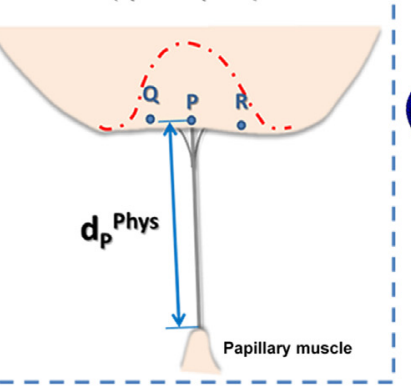

d) LN

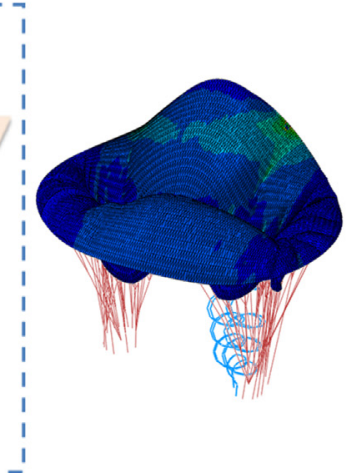

e) LNH

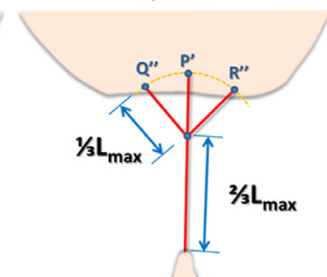

Papillary muscle
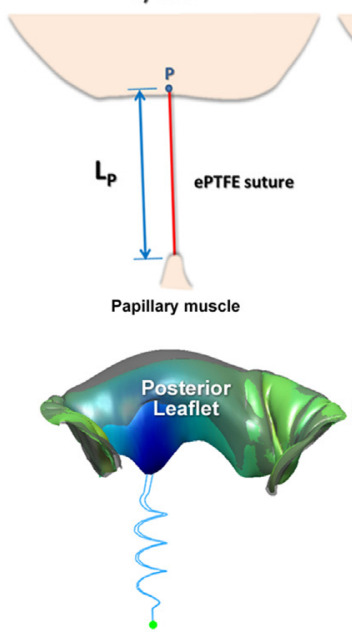

Papillary muscle

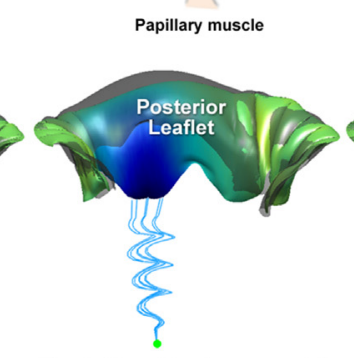

$Z$ relative displacement $[\mathrm{mm}]$

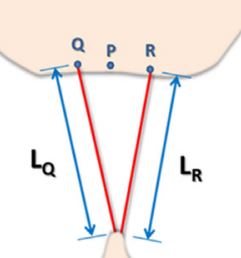

Papillary muscle

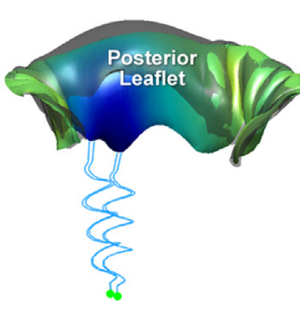

10

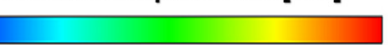

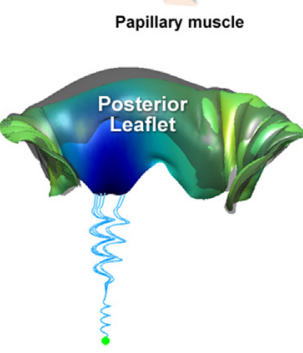

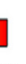

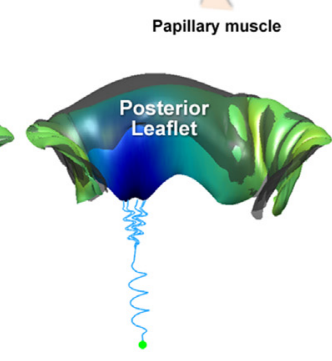

MV Pre-model

FIGURE 1. Study workflow: manual segmentation procedure (1) and computational modeling (2) for a patient-specific MV preoperative geometry with IPP; simulation of the Phys-model (3) and different NCIs with accurate determination of each suture length (4); the contour map of Z relative displacement is reported at peak systole on the posterior leaflet for each NCI postoperative simulation in patient 2 (ePTFE sutures are generally visualized with a springlike appearance). $c M R I$, Cardiac magnetic resonance imaging; $M V$, mitral valve; $I P P$, isolated posterior leaflet prolapse; $N C I$, neochordal implantation; ePTFE, expanded polytetrafluoroethylene; $S N$, single neochordal implantation; $D N$, double neochordal implantation; $S L$, standard loop implantation; $L N$, nonstandard premeasured neochordal implantation with common loop of one third of the entire length; $L N H$, nonstandard premeasured neochordal implantation with common loop of two thirds of the entire length. 
TABLE 1. General characteristics of the patients in the study

\begin{tabular}{lcccc}
\hline & Patient 1 & Patient 2 & Patient 3 & Patient 4 \\
\hline Gender & $\mathrm{F}$ & $\mathrm{M}$ & $\mathrm{F}$ & $\mathrm{F}$ \\
Age $(\mathrm{y})$ & 77 & 75 & 76 & 80 \\
Weight $(\mathrm{kg})$ & 75 & 83 & 60 & 65 \\
Height $(\mathrm{cm})$ & 160 & 168 & 160 & 162 \\
BSA $\left(\mathrm{m}^{2}\right)$ & 1.78 & 1.93 & 1.62 & 1.69 \\
Heart rate $(\mathrm{bpm})$ & 63 & 88 & 65 & 62 \\
A2D/BSA $\left(\mathrm{cm}^{2} / \mathrm{m}^{2}\right)$ & 6.55 & 5.96 & 8.97 & 8.78 \\
$\mathrm{D}_{\mathrm{SL}}(\mathrm{mm})$ & 30.5 & 32.8 & 37.2 & 40.6 \\
$\mathrm{D}_{\mathrm{CC}}(\mathrm{mm})$ & 40.9 & 43.3 & 45.7 & 46.5 \\
e $(-)$ & 1.34 & 1.32 & 1.23 & 1.14 \\
IPP region & $\mathrm{P} 2$ & $\mathrm{P} 2$ & $\mathrm{P} 2-\mathrm{P} 3$ & $\mathrm{P} 2$ \\
\hline
\end{tabular}

$F$, Female; $M$, male; $B S A$, body surface area; $A 2 D$, annular area projection on the mitral valve plane; $D_{S L}$, septolateral diameter; $D_{C C}$, commissural diameter; $e$, eccentricity $\left(\mathrm{D}_{\mathrm{CC}} / \mathrm{D}_{\mathrm{SL}}\right)$; IPP region, main prolapsing scallop in the posterior mitral valve leaflet.

chordal apparatus. For the Phys-model, the systolic peak configuration was computed to obtain a physiologic level of MV coaptation; based on this configuration, proper suture length was determined for 5 different NCI procedures, according to the following criteria:

1. Single neochorda implantation (SN, Figure $1,4, a)$ with suture length approximated in millimeters to the distance $\left(\mathrm{d}_{\mathrm{P}}^{\text {Phys }}\right)$ between the PM tip and the point $(\mathrm{P})$ of neochordal insertion on the MV scallop, as clinically measureable with a surgical caliper;

2. Double neochorda implantation (DN, Figure 1, 4, b) with 2 different sutures arising from the same PM; the lengths were measured separately as in the $\mathrm{SN}$ configuration;

3. Standard neochordal loop (SL, Figure 1, 4,c), made of 3 premeasured neochordae of the same length, arising from a loop tightened to a PM and inserting in the prolapsing leaflet at 3 different points of insertion; neochordal length was set to the maximal distance, in the Phys-model, of the selected points from the PM tip;

4. Nonstandard premeasured loop (LN, Figure 1, 4, d) with a common neochordal loop of one third and 3 different neochordae of two thirds of the entire (PM tip-to-leaflet free margin) length, determined as in the SL configuration;

5. Nonstandard premeasured loop (LNH, Figure 1, 4, e), with 1 neochordal loop of two thirds and 3 different neochordae of one third of the entire length (LNH), determined as in the SL configuration.

\section{Parameters}

Postoperative systolic function was simulated for each NCI and assessed in terms of the following MV biomechanical parameters which were extracted at peak systole from FE simulations: (1) coaptation area (CoA), defined as the area of the region where the anterior and posterior leaflets overlap after MV closure ${ }^{23}$; (2) coaptation length $(\mathrm{CoL})$ between the anterior and posterior leaflets along the prolapsing region, as routinely accessible through transesophageal echocardiography technology ${ }^{24}$; (3) PM forces $\left(\mathrm{F}_{\mathrm{PM}}\right)$, defined as the resultant reaction force produced by $\mathrm{PMs}^{25}$ to bear the tension of both native chordae tendinae and ePTFE sutures; (4) native chordal tension $\left(F_{n c}\right)$, defined as the sum of forces exerted by native chordae tendinae in the proximity of the prolapsing region; (5) artificial chordal tension $\left(\mathrm{F}_{\mathrm{ePTFE}}\right)$ defined as the resultant force exerted by artificial ePTFE neochordae, after NCI; (6) the peak value $\left(\mathrm{S}_{\mathrm{I}}{ }^{\mathrm{MAX}}\right)$ of the maximum principal stresses $S_{I}$, defined as the maximum value of the tensile stress ${ }^{26}$ along the leaflet free margin (ie, where ePTFE was inserted).

All these parameters, with the exception of $\mathrm{F}_{\text {ePTFE }}$ (because it is not available in the Pre-model), were compared with the corresponding preoperative simulation in order to establish potential biomechanical differences between the NCIs performed. For each patient, the entire set of simulations required 1 to 2 weeks of computations, and approximately 2 days of work to segment the cMRI data and carry out the postprocessing of the computational results.

The Institutional Review Board approved the study and informed consent was obtained from each patient.

\section{RESULTS \\ Leaflet Reposition}

In each patient, the use of ePTFE sutures, regardless of the NCI configuration performed, securely repositioned the prolapsing region of the posterior leaflet under the annular plane, resulting in the disappearance of mitral regurgitation and IPP. The maximum displacement of the free margin along the direction normal to the annular plane ( $\mathrm{Z}$ relative displacement) was comparable in all the NCI configurations and equal to $9.9 \pm 0.4 \mathrm{~mm}$ in patient 1 , $10.8 \pm 0.2 \mathrm{~mm}$ in patient $2,6.2 \pm 0.1 \mathrm{~mm}$ in patient 3 , and $7.3 \pm 0.1 \mathrm{~mm}$ in patient 4 . However, compared with $\mathrm{SN}$, implantation of multiple neochordae improved the repair in the prolapsing region because a wider realignment of the free margin along the prolapsed P2 region was noticed, as highlighted in the contour maps of the relative $\mathrm{Z}$ displacement in the NCI simulations (Figure 1,4) (ie, the extent of the blue areas increased in each postoperative model; the preoperative leaflet surface is shown in a transparent gray color). Moreover, the repaired region of the P2 scallop (ie, the area of P2 from the midline to the P3) looked more like the morphologic configuration of its counterpart segment constituting the P2 scallop (ie, the area of P2 from the midline to the P1 scallop) at peak systole.

\section{Coaptation Area and Length}

A marked CoA recovery was noticed in all NCI simulations; however, the best CoA recovery in each patient was achieved with different NCI techniques, according to the anatomy of the disease and the location of the prolapsing region (Table 2, CoA section). In all patients, the lowest CoA recovery was noticed with the $\mathrm{SN}$ configuration $(+22.5 \%$ in patient $1,+14.2 \%$ in patient $2,+3.5 \%$ in patient 3 , and $+19.4 \%$ in patient 4 ). Throughout the set of simulations, the maximal recovery of CoA in each patient was achieved through multiple ePTFE sutures and in particular adopting $\mathrm{LN}(+33.2 \%)$ and SL $(+32.3 \%)$ in patient $1, \mathrm{DN}(+33.0 \%)$ and $\mathrm{LNH}(+32.6 \%)$ in patient 2 , LNH $(+28.7 \%)$ in patient 3 , LNH $(+20.9 \%)$, and SL $(+20.7 \%)$ in patient 4 .

In the prolapsing region of each preoperative model, $\mathrm{CoL}$ was absent as a result of IPP; a portion of the free margin of the prolapsing scallop thus resulted in no coaptation as shown in Figure 2, A.

After NCIs, for each patient, $\mathrm{CoL}$ was restored and its mean value was equal to $6.0 \pm 0.3 \mathrm{~mm}$ in patient $1,6.7 \pm 0.4 \mathrm{~mm}$ in 
TABLE 2. Computed coaptation area (CoAs), coaptation length in the prolapsing region (CoLs), native chordae tension in the prolapsing region $\left(F_{n c}\right)$, ePTFE neochordae tension $\left(F_{\text {ePTFE }}\right)$, papillary muscle reaction force $\left(F_{P M}\right)$, and peak value of $S_{I}$ stress $\left(S_{I}{ }^{M A X}\right)$ along the posterior free margin in preoperative models (IPP, where available) and after different neochordal implantations*

\begin{tabular}{|c|c|c|c|c|}
\hline & Patient 1 & Patient 2 & Patient 3 & Patient 4 \\
\hline \multicolumn{5}{|c|}{$\mathrm{CoA}\left(\mathrm{mm}^{2}\right)$} \\
\hline IPP & 129.7 & 203.1 & 176.1 & 204.5 \\
\hline SN & $159.0(+22.5)$ & $232.0(+14.2)$ & $182.3(+3.5)$ & $244.2(+19.4)$ \\
\hline $\mathrm{DN}$ & $159.5(+23.0)$ & $270.1(+33.0)$ & $220.6(+25.3)$ & $244.9(+19.7)$ \\
\hline SL & $171.6(+32.3)$ & $259.7(+27.8)$ & $215.7(+22.5)$ & $246.8(+20.7)$ \\
\hline $\mathrm{LN}$ & $172.8(+33.2)$ & $246.8(+21.5)$ & $204.0(+15.9)$ & $245.7(+20.1)$ \\
\hline LNH & $164.7(+27.0)$ & $269.3(+32.6)$ & $226.6(+28.7)$ & $247.3(+20.9)$ \\
\hline \multicolumn{5}{|c|}{$\operatorname{CoL}(\mathrm{mm})$} \\
\hline IPP & - & - & - & - \\
\hline $\mathrm{SN}$ & 5.74 & 6.17 & 4.57 & 7.19 \\
\hline $\mathrm{DN}$ & 5.71 & 7.15 & 5.78 & 7.48 \\
\hline SL & 6.25 & 6.73 & 5.44 & 7.58 \\
\hline $\mathrm{LN}$ & 6.41 & 6.56 & 5.47 & 7.53 \\
\hline LNH & 5.94 & 6.99 & 5.80 & 7.60 \\
\hline \multicolumn{5}{|l|}{$F_{n c}(N)$} \\
\hline IPP & 3.21 & 3.99 & 3.72 & 2.56 \\
\hline $\mathrm{SN}$ & $2.50(-22.2)$ & $2.70(-32.4)$ & $2.89(-22.2)$ & $2.25(-11.8)$ \\
\hline DN & $2.34(-27.2)$ & $2.41(-39.6)$ & $2.42(-34.9)$ & $2.16(-15.6)$ \\
\hline SL & $2.41(-24.9)$ & $2.38(-40.4)$ & $3.09(-17.0)$ & $2.09(-18.3)$ \\
\hline $\mathrm{LN}$ & $2.25(-29.9)$ & $2.28(-42.9)$ & $2.63(-29.4)$ & $2.09(-18.3)$ \\
\hline LNH & $2.26(-29.7)$ & $2.42(-39.4)$ & $2.60(-30.1)$ & $2.07(-19.1)$ \\
\hline \multicolumn{5}{|c|}{$\mathrm{F}_{\mathrm{ePTFE}}(\mathrm{N})$} \\
\hline IPP & - & - & - & - \\
\hline $\mathrm{SN}$ & 0.94 & 1.31 & 0.65 & 0.59 \\
\hline DN & 1.06 & 1.54 & 0.76 & 0.75 \\
\hline SL & 1.00 & 1.50 & 0.67 & 0.86 \\
\hline $\mathrm{LN}$ & 1.07 & 1.48 & 0.78 & 0.87 \\
\hline LNH & 1.12 & 1.53 & 0.76 & 0.88 \\
\hline \multicolumn{5}{|l|}{$\mathrm{F}_{\mathrm{PM}}(\mathrm{N})$} \\
\hline IPP & 14.08 & 13.58 & 15.48 & 17.57 \\
\hline $\mathrm{SN}$ & $13.39(-4.9)$ & $12.42(-8.6)$ & $14.77(-4.6)$ & $17.22(-2.0)$ \\
\hline DN & $13.04(-7.4)$ & $12.15(-10.5)$ & $14.62(-5.6)$ & $17.16(-2.4)$ \\
\hline SL & $13.22(-6.1)$ & $12.20(-10.2)$ & $15.36(-0.8)$ & $17.14(-2.5)$ \\
\hline $\mathrm{LN}$ & $13.11(-6.9)$ & $12.15(-10.5)$ & $15.02(-2.9)$ & $17.16(-2.4)$ \\
\hline LNH & $13.16(-6.5)$ & $11.78(-13.3)$ & $15.06(-2.7)$ & $17.14(-2.5)$ \\
\hline \multicolumn{5}{|c|}{$\mathrm{S}_{\mathrm{I}}^{\mathrm{MAX}}(\mathrm{kPa})$} \\
\hline IPP & 272.0 & 349.1 & 145.6 & 364.1 \\
\hline $\mathrm{SN}$ & $270.8(-0.4)$ & $337.8(-3.2)$ & $225.8(+55.1)$ & $267.4(-26.6)$ \\
\hline DN & $254.5(-6.5)$ & $248.7(-28.8)$ & $165.1(+13.4)$ & $227.2(-37.6)$ \\
\hline SL & $202.7(-25.5)$ & $245.8(-29.6)$ & $111.4(-23.5)$ & $231.6(-36.4)$ \\
\hline $\mathrm{LN}$ & $201.1(-26.1)$ & $287.9(-17.5)$ & $189.1(+29.8)$ & $223.9(-38.5)$ \\
\hline LNH & $200.6(-26.2)$ & $284.8(-18.4)$ & $179.1(+23.0)$ & $242.4(-33.4)$ \\
\hline
\end{tabular}

$I P P$, Isolated posterior leaflet prolapse; $S N$, single neochordal implantation; $D N$, double neochordal implantation; $S L$, standard loop implantation; $L N$, nonstandard premeasured neochordal implantation with common loop of one third of the entire length; $L N H$, nonstandard premeasured neochordal implantation with common loop of two thirds of the entire length; $C o A$, coaptation area; $C o L$, coaptation length; $F_{n c}$, native chordal tension; $F_{e P T F E}$, artificial suture tension; $F_{P M}$, papillary muscles forces; $S_{I}^{M A X}$, peak value of maximum principal stresses along the leaflet free margin. *Percentage variations with respect to IPP models are reported in brackets.

patient 2, $5.4 \pm 0.5 \mathrm{~mm}$ in patient 3 , and $7.5 \pm 0.2 \mathrm{~mm}$ in patient 4 ; in accordance with the CoA recovery results, the highest $\mathrm{CoL}$ values were obtained using multiple NCI: $\mathrm{LN}(6.41 \mathrm{~mm})$ in patient $1, \mathrm{DN}(7.15 \mathrm{~mm})$ in patient 2 , LNH $(5.80 \mathrm{~mm})$ in patient 3 , and $\mathrm{LNH}(7.60 \mathrm{~mm})$ in patient 4.

\section{PM Forces}

In all NCI models, a slight reduction in PM reaction force was noticed (Table 2, $\mathrm{F}_{\mathrm{PM}}$ section). The highest decrease in PM force was measured in the DN configuration in patients 1 and $3(-7.4 \%$ and $-5.6 \%$, respectively), in the $\mathrm{LNH}$ configuration $(-13.3 \%)$ in 


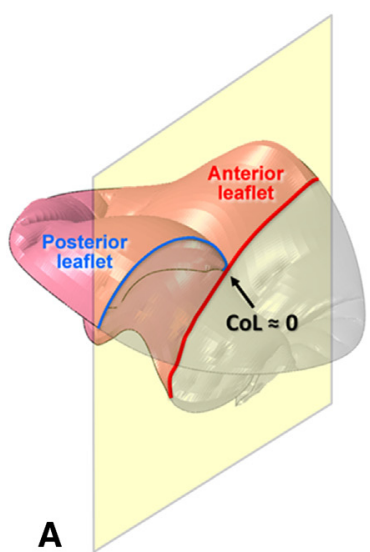

SN

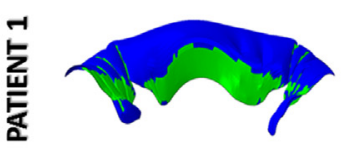

点
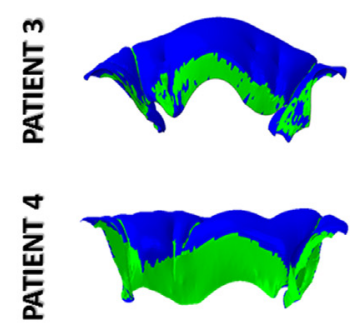

PATIENT 1

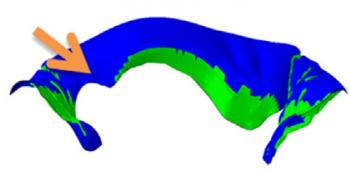

Pre-models

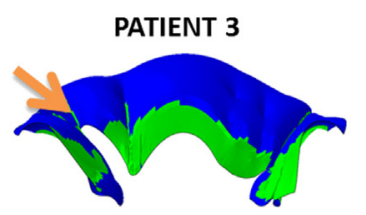

B

\section{Coaptation Area}

SL
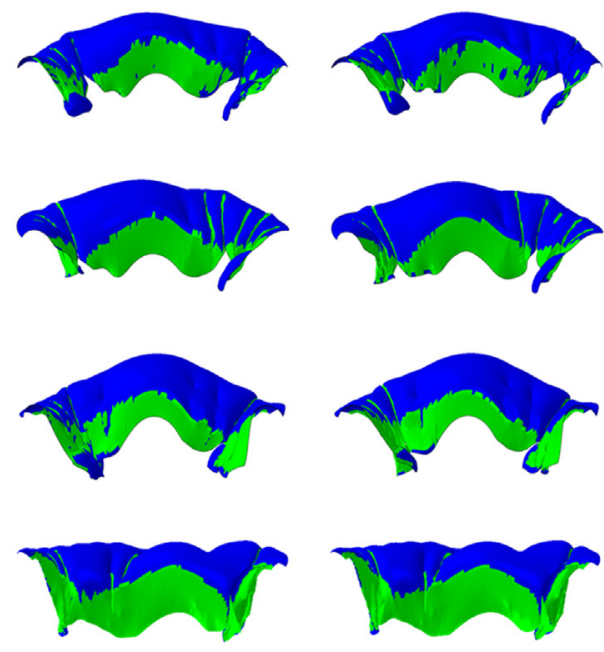

PATIENT 2

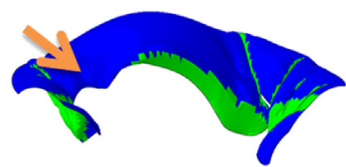

PATIENT 4

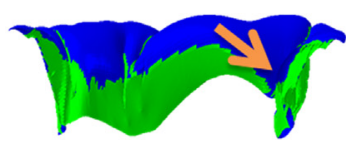

C

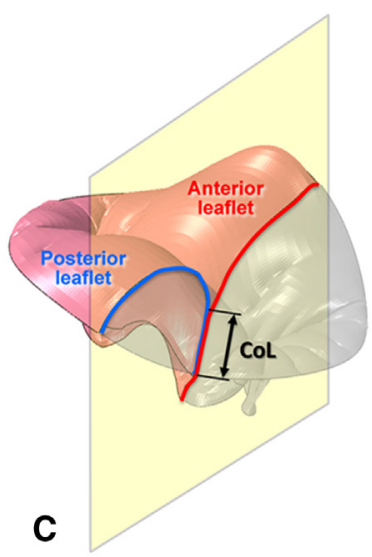

LNH

D

FIGURE 2. Coaptation length $(\mathrm{CoL})$ on the prolapsing posterior leaflet of patient 2 Pre-model (A); coaptation area (B) in each Pre-model (for each patient, the arrow indicates the region of no coaptation as a result of leaflet prolapse); CoL on the posterior leaflet of patient 2 after NCI (C, SL configuration); contour maps of CoA (shown in green) after NCIs, for each patient (D). SN, Single neochordal implantation; DN, double neochordal implantation; $S L$, standard loop implantation; $L N$, nonstandard premeasured neochordal implantation with common loop of one third of the entire length; $L N H$, nonstandard premeasured neochordal implantation with common loop of two thirds of the entire length.

patient 2 , and either in the $\mathrm{LNH}(-2.5 \%)$ or SL $(-2.5 \%)$ configuration in patient 4 .

\section{Native Chordal Tension}

In all NCI models, chordal tension of the prolapsing region was partially transferred from the intact native chordae to the ePTFE sutures. The reaction forces exerted by the native and intact chordae, adjacent to the prolapsing region, are reported in Table 2 ( $\mathrm{F}_{\mathrm{nc}}$ section). The range of percentage force reduction was $22 \%$ to $30 \%, 32 \%$ to $43 \%, 17 \%$ to $35 \%$, and $12 \%$ to $19 \%$ for each patient respectively, based on the technique used. Overall, a decrease in reaction forces was obtained going from SN to multiple NCIs. The difference in chordal tension $\mathrm{F}_{\mathrm{nc}}$ between the Pre-model and each NCI was highest in LN repair for patients 1 and $2(0.96 \mathrm{~N}$, and $1.71 \mathrm{~N})$, DN repair for patient $3(1.3 \mathrm{~N})$, and $\mathrm{LNH}$ repair for patient $4(0.49 \mathrm{~N})$.

\section{Artificial Chordal Tension}

The force exerted by artificial ePTFE sutures was computed at peak systole for each patient (Table 2, $\mathrm{F}_{\mathrm{ePTFE}}$ section). Although different NCIs were performed, negligible differences in terms of tension were reported on the ePTFE sutures $(1.04 \pm 0.07 \mathrm{~N}$ in patient $1,1.47 \pm 0.09 \mathrm{~N}$ in patient 2, $0.72 \pm 0.06 \mathrm{~N}$ in patient 3, and $0.79 \pm 0.12$ $\mathrm{N}$ in patient 4).

\section{Stress Analysis}

In the Pre-model of each patient, low $S_{I}$ stresses were reported on the prolapsing segment of the posterior leaflet; 

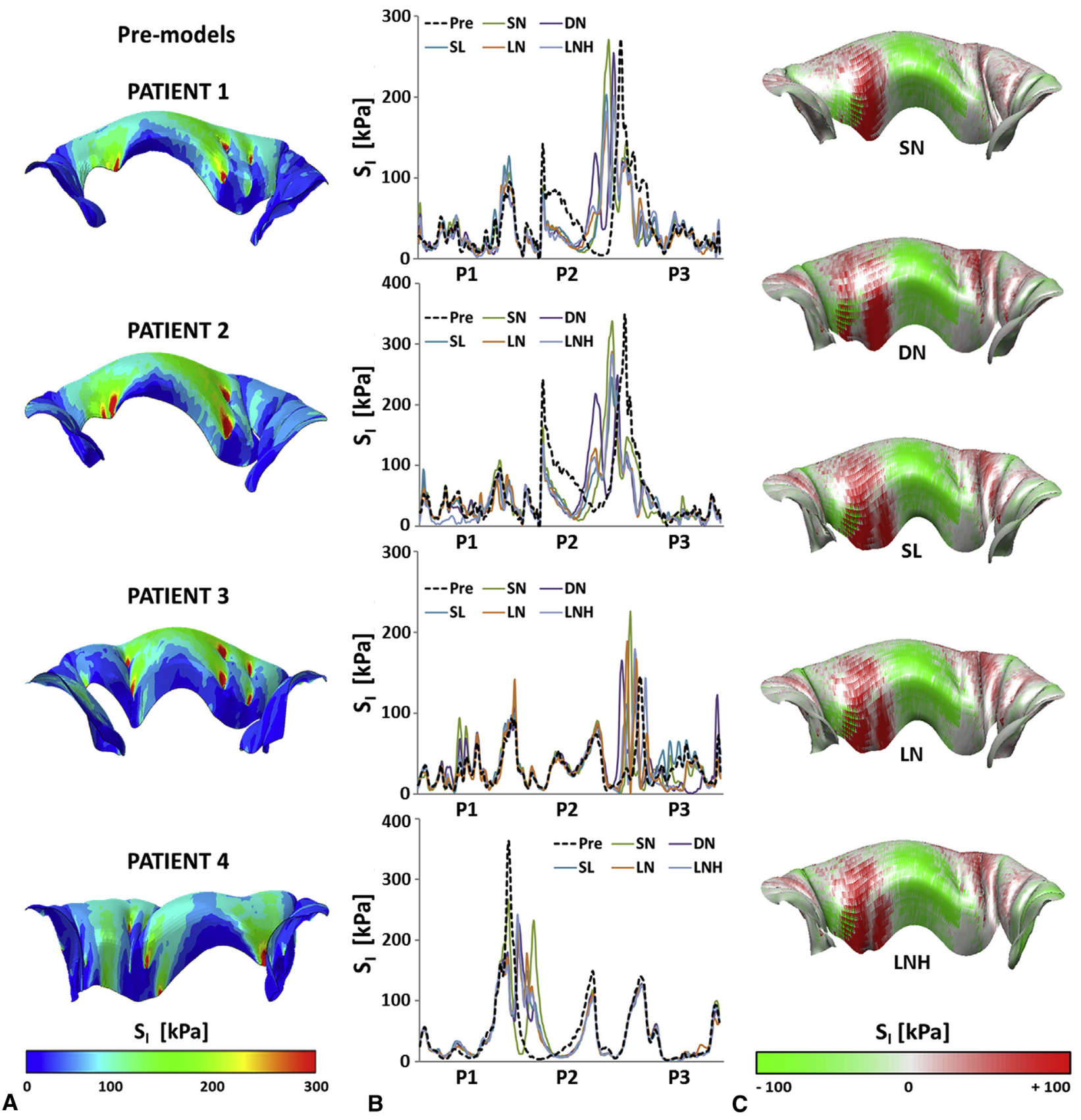

FIGURE 3. Results of stress analysis. A, Contour map of $S_{I}$ stresses in the preoperative conditions for each patient (Pre-models); B, spatial distribution of $S_{I}$ stress along the free margin of the posterior mitral scallops (P1, P2, and P3); C, contour map of the variation in relative $\mathrm{S}_{\mathrm{I}}$ stresses between each NCI model and the Pre-model for patient 2. SN, Single neochordal implantation; $D N$, double neochordal implantation; $S L$, standard loop implantation; $L N$, nonstandard premeasured neochordal implantation with common loop of one third of the entire length; $L N H$, nonstandard premeasured neochordal implantation with common loop of two thirds of the entire length.

in contrast, concentrations of $S_{\text {I }}$ stresses were reported in the proximity of the prolapsing region, and in particular: (1) along the free margin of P2 scallop close to the insertion of intact native chordae as highlighted in patients 1,2, and 4 (Figure 3, A); (2) on the adjacent posterior scallop P3, as found in patient 3 , whose prolapse was located in proximity of the P2-P3 cleft area. The maximum value of stress $\mathrm{S}_{\mathrm{I}}{ }^{\mathrm{MAX}}$ was extracted for each Pre-model, along the free margin of the posterior leaflet and found to be equal to $272.0 \mathrm{kPa}$, $349.1 \mathrm{kPa}, 145.6 \mathrm{kPa}$, and $364.1 \mathrm{kPa}$, in each patient, respectively. In patient $3, \mathrm{~S}_{\mathrm{I}}$ stresses were markedly lower compared with the other patients; the location of prolapse 
in patient 3 was found to be more lateral (ie, nearer to P3 scallop) than in the other patients; their prolapse mainly involved the central P2 scallop.

In postoperative simulations, $\mathrm{S}_{\mathrm{I}}$ stresses were computed along the free margin of the entire posterior leaflet and are reported graphically in Figure 3, $B$, in order to spatially assess and compare the result of different NCIs. $\mathrm{S}_{\mathrm{I}}$ stresses along the nonprolapsing scallops were substantially unchanged between pre- and postoperative analyses, regardless of the technique used. In contrast, $S_{I}$ stresses changed noticeably on the prolapsing scallop, with postoperative reduction in the areas subtended by native chordae (thus, far from the neochordal insertion), regardless of the technique used, with a redistribution of $S_{I}$ stresses at the level of neochordal insertion.

The distribution and magnitude of $\mathrm{S}_{\mathrm{I}}$ stresses on neochordal insertion proved to be technique specific. In all patients, the highest values of $\mathrm{S}_{1}{ }^{\mathrm{MAX}}$ were found after implantation of a single neochorda (SN, $270.8 \mathrm{kPa}, 337.8 \mathrm{kPa}, 225.8 \mathrm{k}$ $\mathrm{Pa}$, and $267.4 \mathrm{kPa}$ for each patient, respectively), whereas the highest reduction in $\mathrm{S}_{\mathrm{I}}{ }^{\mathrm{MAX}}$ was achieved through multiple NCIs, in particular with LNH in patient $1(200.6 \mathrm{kPa}$, $-26.2 \%$ from the Pre-model), SL in both patient $2(245.8$ $\mathrm{kPa},-29.6 \%)$ and patient $3(111.4 \mathrm{kPa},-23.5 \%)$, and $\mathrm{LN}$ in patient $4(223.9 \mathrm{kPa},-38.5 \%)$. Moreover, in patients 1,2 , and $4, \mathrm{~S}_{1}{ }^{\mathrm{MAX}}$ was lower than in the Pre-model for each $\mathrm{NCI}$; in contrast, only the SL configuration achieved a noticeably lower value of $\mathrm{S}_{1}{ }^{\mathrm{MAX}}$ with respect to the Premodel in patient 3 . The values of $\mathrm{S}_{1}{ }^{\mathrm{MAX}}$ along the free margin of each model are detailed in Table 2.

In order to assess the postoperative distribution of $S_{I}$ stresses, the contour map of the relative variation of $\mathrm{S}_{\mathrm{I}}$ stresses (ie, the difference in $S_{I}$ stresses between each NCI model and the Pre-model) is reported for patient 2, at peak systole, in Figure 3,C. From a qualitative point of view, equivalent patterns of $S_{I}$ stresses were identified in postoperative simulations, regardless of the surgical technique used, because in a large area of the P2 scallop, stress decreased (green area), thus indicating unloading of the native chordae and relief of excessive mechanical stress on leaflet tissue. In the repaired part of the posterior leaflet, $\mathrm{S}_{\mathrm{I}}$ stresses increased after NCI (red area) because ePTFE sutures restored mechanical tension along the prolapsing region of the leaflet. Moreover, going from the SN configuration to multiple NCI, the above-mentioned progressive decrease in $\mathrm{S}_{\mathrm{I}}{ }^{\mathrm{MAX}}$ was combined with a larger mechanical redistribution of $S_{I}$ stresses along the restored part of the MV leaflet.

\section{DISCUSSION}

The present study clearly shows, for the first time, that relocation of the posterior MV leaflet with different NCI techniques can have different consequences on MV biomechanics, despite comparable macroscopic successful surgery, as demonstrated by the absence of any residual mitral regurgitation and by the restoration of adequate values of $\mathrm{CoL}$ and $\mathrm{CoA}$. Furthermore, we were able to demonstrate that the biomechanics of the prolapsed posterior leaflet change, based on the underlying mechanisms of IPP, and similar changes are noticeable postoperatively, in a technique-specific fashion. We report that, through an integrated bioengineering-radiological-surgical approach to the simulation of MV apparatus, the reliability of FE analysis clearly increases, with the potential for both an elegant reproduction of different surgical repairs and a detailed definition of the postoperative biomechanical changes associated with several NCI techniques.

According to our data, it is possible to define a theoretic patient-specific gold standard NCI technique for any patient, in terms of both macroscopic and biomechanical characteristics. CoA and $\mathrm{CoL}$ can be considered as macroscopic pivotal parameters (surgery generally aims to maximize both parameters); however, biomechanical variables, such as the relief of tension on the native chordae, the degree of stress redistribution on MV leaflets, and peak mechanical stresses observed along the leaflet free margin after NCI, although not directly measureable by surgeons, may play a crucial role in defining the best repair technique. As examples, in patients 1 and 4 (who shared a similar but specular mechanism of isolated $\mathrm{P} 2$ prolapse), $\mathrm{LN}$ and $\mathrm{LNH}$, respectively, proved to be the best available surgical options, because they individually combined the highest recovery of $\mathrm{CoA}$ and $\mathrm{CoL}$ with the highest relief of tension on the native chordae $\left(\mathrm{F}_{\mathrm{nc}}\right)$, leaving the reaction forces of the $\mathrm{PM}\left(\mathrm{F}_{\mathrm{PM}}\right)$ substantially unchanged and achieving significant reduction of $\mathrm{S}_{\mathrm{I}}^{\mathrm{MAX}}$ along the free margin. According to these findings, it can also be argued that a correlation between FE-derived biomechanics at the time of the repair and clinical long-term follow-up of different techniques for NCIs (eg, via a recurrence of MV regurgitation) may help to elucidate which of the biomechanical variables might play a crucial role in the fate of MV repair. Sporadic primary failure of ePTFE neochordae, as well as several case reports of neochoral calcification and fracture, have been reported in the literature. ${ }^{27,28}$

Postoperative changes in MV biomechanics assessed with cMRI-derived FE models can provide valuable background to better understand the biomechanical implications after surgical repair. Preoperative stresses are usually concentrated on the leaflet areas next to the prolapse (as graphically reported in Figure 3); moreover, these stresses might have acted, with their potential weakening effect, on those areas for a long time before repair. Therefore, although we reported that all the NCI techniques transferred these stresses back on the prolapsed area (clinical practice with NCI is almost always a success story), adjacent areas may remain weak and be the potential initial source for future relapse of IPP (possibly due also to a 
more rapid progression of the remodeling processes of MV degeneration, triggered by the long-lasting stresses on these areas). It is common practice to reoperate on patients with recurrent mitral leaflet prolapse without evidence of NCI failure, as reported in most clinical series. $^{8,29}$ These data could suggest that multiple neochordal stitching involving the areas next to the prolapsed region, although unusual in current surgical practice, might be considered in order to reinforce those chronically weakened areas, thus potentially ameliorating the long-term clinical results.

Our cMRI-derived FE models confirmed the clinical hypothesis, ${ }^{9,30}$ according to which multiple ePTFE neochordae can provide a larger leaflet coaptation area, better preserve the ventriculo-annular continuity, and better redistribute stresses on the repaired leaflet. As clinically supposed, in our simulations the largest CoA and the highest reduction of $S_{I}{ }^{M A X}$ along the free margin were achieved with multiple NCIs. As for patients 1, 2, and 4, patient 3 also showed a progressive decline of $\mathrm{S}_{\mathrm{I}}{ }^{\mathrm{MAX}}$ along the free margin going from $\mathrm{SN}$ to loop techniques. However, the unexpected increase, with respect to the Pre-model, in $\mathrm{S}_{\mathrm{I}}{ }^{\mathrm{MAX}}$ of $\mathrm{LN}(+29.8 \%)$ and $\mathrm{LNH}(+23.0 \%)$ in patient 3 , compared with its reduction only with the SL configuration $(-23.5 \%)$, deserves further speculation. We hypothesized that it can be related to a higher spatial flexibility, compared with a relatively more constraining effect with $\mathrm{LN}$ and $\mathrm{LNH}$ configurations, offered by the SL configuration, where artificial neochordae can better adapt to the postoperative geometry, thus achieving a more physiologic redistribution of stresses along both P2 and P3 free margins. Future studies are needed to further investigate the peculiar biomechanics of paramedial P2 prolapse and to confirm these preliminary speculations.

In conclusion, FE patient-specific simulations highlighted biomechanical differences in the outcome of several NCI configurations. The tests performed may potentially affect the clinical outcome of the procedure and promote, if extensively and successfully tested, patient-specific optimization of NCI techniques for the treatment of degenerative MV prolapse. Compared with, for example, transesophageal echocardiography, cMRI involves higher costs and is less convenient. However, it allows for a more reliable $3 \mathrm{D}$ reconstruction of the morphology of the entire mitral apparatus and of the complete kinematics of its substructures. The impact of valve morphology and kinematic boundary conditions on the computed biomechanical variables $^{31}$ led to the use of a cMRI-based modeling approach.

\section{Limitations}

The present study has 3 main limitations. First, it is based on the analysis of a small cohort of patients with IPP. However, according to the speculative nature of the study, each anatomic substrate served as a benchmark for biomechanical tests on 5 different surgical NCI techniques.

Second, to date there is no clinical proof of a biomechanical-induced relapse of IPP, because we do not have any long-term follow-up data for the patients in the study. As a consequence, we cannot translate our quantitative results, which refer to an acute postoperative condition, into long-term prognostic indicators.

Third, the modeling methodology adopted requires a considerable amount of computational and human work, which is not compatible with its use in routine clinical application.

Accordingly, in order to overcome these limitations, future efforts will focus on further expansion of these preliminary results through the enrollment of more patients and their monitoring over a long-term follow-up. Also, in order to develop more clinically oriented tools, we are already exploring different modeling approaches that, at the cost of a less detailed quantification of biomechanical variables (ie, local strains and stresses), will allow fast and almost real-time simulations. ${ }^{32}$ Increasing the cohort of patients will provide an improved correlation between the biomechanical differences and the clinical outcomes of different surgical techniques and help to stratify, based on a larger range of MV prolapse patterns, the potential clinical risks associated with some MV repairs.

\section{References}

1. Iung B, Baron G, Butchart EG, Delahaye F, Gohlke-Barwolf C, Levang OW, et al. A prospective survey of patients with valvular heart disease in Europe: the Euro Heart Survey on Valvular Heart Disease. Eur Heart J. 2003; 24:1231-43

2. Carpentier A. Cardiac valve surgery-the "French correction". J Thorac Cardiovasc Surg. 1983;86:323-37.

3. Perier P, Hohenberger W, Lakew F, Batz G, Urbanski P, Zacher M, et al. Toward a new paradigm for the reconstruction of posterior leaflet prolapse: midterm results of the "respect rather than resect' approach. Ann Thorac Surg. 2008;86:718-25.

4. Calafiore AM. Choice of artificial chordae length according to echocardiographic criteria. Ann Thorac Surg. 2006;81:375-7.

5. Duran CM, Pekar F. Techniques for ensuring the correct length of new mitral chords. J Heart Valve Dis. 2003;12:156-61.

6. Mandegar MH, Yousefnia MA, Roshanali F. Preoperative determination of artificial chordae length. Ann Thorac Surg. 2007;84:680-2.

7. Adams DH, Kadner A, Chen RH. Artificial mitral valve chordae replacement made simple. Ann Thorac Surg. 2001;71:1377-8.

8. Salvador L, Mirone S, Bianchini R, Regesta T, Patelli F, Minniti G, et al. A 20-year experience with mitral valve repair with artificial chordae in 608 patients. J Thorac Cardiovasc Surg. 2008;135:1280-7.

9. Scorsin M, Al-Attar N, Lessana A. A novel technique of utilizing artificial chordae for repair of mitral valve prolapse. J Thorac Cardiovasc Surg. 2007; 134:1072-3

10. Adams DH, Anyanwu AC, Rahmanian PB, Filsoufi F. Current concepts in mitral valve repair for degenerative disease. Heart Fail Rev. 2006;11:241-57.

11. Votta E, Le TB, Stevanella M, Fusini L, Caiani EG, Redaelli A, et al. Toward patient-specific simulations of cardiac valves: state-of-the-art and future directions. J Biomech. 2013;46:217-28.

12. Reimink MS, Kunzelman KS, Cochran RP. The effect of chordal replacement suture length on function and stresses in repaired mitral valves: a finite element study. J Heart Valve Dis. 1996;5:365-75.

13. Kunzelman K, Reimink MS, Verrier ED, Cochran RP. Replacement of mitral valve posterior chordae tendineae with expanded polytetrafluoroethylene suture: a finite element study. J Card Surg. 1996;11:136-45. 
14. Rim Y, Laing ST, McPherson DD, Kim H. Mitral valve repair using ePTFE sutures for ruptured mitral chordae tendineae: a computational simulation study. Ann Biomed Eng. 2014;42:139-48.

15. Stevanella M, Maffessanti F, Conti CA, Votta E, Arnoldi A, Lombardi M, et al. Mitral valve patient-specific finite element modeling from cardiac MRI: application to an annuloplasty procedure. Cardiovasc Eng Technol. 2011;2: 66-76.

16. Lam JH, Ranganathan N, Wigle ED, Silver MD. Morphology of the human mitral valve. I. Chordae tendineae: a new classification. Circulation. 1970;41: 449-58.

17. Ranganathan N, Lam JH, Wigle ED, Silver MD. Morphology of the human mitral valve. II. The value leaflets. Circulation. 1970;41:459-67.

18. Degandt AA, Weber PA, Saber HA, Duran CM. Mitral valve basal chordae: comparative anatomy and terminology. Ann Thorac Surg. 2007;84: 1250-5.

19. May-Newman K, Yin FC. A constitutive law for mitral valve tissue. J Biomech Eng. 1998;120:38-47.

20. Kunzelman KS, Cochran RP. Mechanical properties of basal and marginal mitral valve chordae tendineae. ASAIO Trans. 1990;36:M405-8.

21. Dang MC, Thacker JG, Hwang JC, Rodeheaver GT, Melton SM, Edlich RF. Some biomechanical considerations of polytetrafluoroethylene sutures. Arch Surg. 1990; 125:647-50.

22. Votta E, Paroni L, Conti CA, Pelosi A, Mangini A, D'Alesio P, et al. Aortic valve repair via neo-chordae technique: mechanistic insight through numerical modelling. Ann Biomed Eng. 2012;40:1039-51.

23. Maffessanti F, Marsan NA, Tamborini G, Sugeng L, Caiani EG, Gripari P, et al. Quantitative analysis of mitral valve apparatus in mitral valve prolapse before and after annuloplasty: a three-dimensional intraoperative transesophageal study. J Am Soc Echocardiogr. 2011;24:405-13.

24. Gogoladze G, Dellis SL, Donnino R, Ribakove G, Greenhouse DG, Galloway A, et al. Analysis of the mitral coaptation zone in normal and functional regurgitant valves. Ann Thorac Surg. 2010;89:1158-61.

25. Vismara R, Pavesi A, Votta E, Taramasso M, Maisano F, Fiore GB. A pulsatile simulator for the in vitro analysis of the mitral valve with tri-axial papillary muscle displacement. Int J Artif Organs. 2011;34:383-91.

26. Ragab A-RA, Bayoumi SEA. Engineering Solid Mechanics: Fundamentals and Applications. Boca Raton, FL: CRC Press; 1998:944.

27. Coutinho GF, Carvalho L, Antunes MJ. Acute mitral regurgitation due to ruptured ePTFE neo-chordae. J Heart Valve Dis. 2007;16:278-81.

28. Butany J, Collins MJ, David TE. Ruptured synthetic expanded polytetrafluoroethylene chordae tendinae. Cardiovasc Pathol. 2004;13:182-4.

29. Kobayashi J, Sasako Y, Bando K, Minatoya K, Niwaya K, Kitamura S. Ten-year experience of chordal replacement with expanded polytetrafluoroethylene in mitral valve repair. Circulation. 2000;102:III30-4.

30. Falk V, Seeburger J, Czesla M, Borger MA, Willige J, Kuntze T, et al. How does the use of polytetrafluoroethylene neochordae for posterior mitral valve prolapse (loop technique) compare with leaflet resection? A prospective randomized trial. J Thorac Cardiovasc Surg. 2008;136:1205; discussion 1206.
31. Stevanella M, Votta E, Redaelli A. Mitral valve finite element modeling: implications of tissues' nonlinear response and annular motion. J Biomech Eng. 2009; 131:4000107.

32. Hammer PE, Sacks MS, del Nido PJ, Howe RD. Mass-spring model for simulation of heart valve tissue mechanical behavior. Ann Biomed Eng. 2011;39: 1668-79.

\section{Discussion}

Dr Daniel H. Drake (Traverse City, Mich). I congratulate you on your superb work. Finite element analysis is essential to further our understanding of complex repair. There is increasing evidence to suggest that Barlow disease is a subtle connective disorder resulting in biomechanically weak tissue. Therefore, in accordance with the Law of Laplace, shouldn't we try to reduce the size of the annulus in order to decrease the load on all structures within the mitral apparatus?

Is there finite element evidence to support reductive-ring annuloplasty or at least true-size ring annuloplasty for the patient with Barlow disease?

Dr Sturla. Thanks for the question. We have to distinguish between the 2 groups. We have to distinguish fibroelastic deficiency, for example, from the patients with Barlow disease. In this study, all the patients were affected by fibroelastic deficiency and we can infer that mechanical stress can be really redistributed on the leaflet, thus obtaining good results.

In the future, I would like to extend my analysis to some more difficult cases, such as cases of Barlow disease for which we have to go deeper into the problem, and assessing this point could be very interesting.

Dr Drake. Thank you.

Dr Kenton J. Zehr (Baltimore, $M d$ ). Can I ask 1 quick question? Have you looked at the effect of respecting the leaflet versus resecting the leaflet?

Dr Sturla. At the moment, not yet. With regard to the resection technique, we are going to make adequate biomechanical assumptions to simulate it; I am going to study this aspect and I hope make it.

Dr Zehr. Very nice. We look forward to it.

Dr Sturla. Thank you. 